\title{
¿Se plantearon en el Perú virreinal los grandes problemas culturales?
}

Grave y profunda cuestión histórica es investigar si, en el Perú colonial, la mentalidad criolla y la mestiza pugnaron por captar los grandes movimientos ideológicos que cambiaron la facetas de la vida, en la Europa del Renacimiento y de la Reforma. La finalidad, clara y nítida, del esfuerzo investigatorio, Cdebe condensarsel asi: :Hubo Renacimiento en el Perúecoloniah? \&Enoquémomento histórico se puede descubrir el arte del renacentismo peruano?

La Historia, ciencia indudable de la vida social humana, tiene, entre sus atributos culturizadores, uno, singularísimo, que califica su cientifismo hominal: actualizar el pasado; o sea, revivir los gérmenes más remotos de la cultura de los pueblos, para delinear la espiral evolutiva de la mentalidad, en función del ambiente geográfico y del intercambio ideológico con las naciones coetáneas.

Y esta soberana función de la Historia, que vuelcan las Cátedras de Fuentes Históricas del Perú e Historia de la Civilización Antigua y Media, del Dr. Urteaga; el Curso de Investigación en Historia del Perú, del Dr. Basadre; 
en Historia de la Cultura, del Dr. Cabada, etc., en la Facultad de Letras de San Marcos; constituye mi máxima inquietud de maestro y de investigador de la vida colonial y republicana del país.

Me preocupa, siempre, que el alumnado, en posesión de los elementos aportados por el maestro, plantee y resuelva, por sí mismo, en cada matiz de la vida peruana, un problema histórico, que es, en esencia, un problema social de actualidad y que interesa, personalmente, al estudiante, y a la nación en general.

En el caso del epígrafe, la cuestión es trascendente. Se trata de saber si el gran movimiento espiritual de la Europa Moderna, que calificó toda una Epoca histórica, ingresó al Perú y si influyó en la formación de una cultura genuinamente peruana, adecuada al ambiente geográfico y a la sociabilidad de aquellos siglos de predominio español.

La complejidad de elementos, que concurren, históricamente, para esquematizar el problema, puede enunciarse de este modo:
a) E-Elementos políticos Conversom
b) - " $\quad$ legales
c) 一 , sociales
d) - , culturales
e) - " económicos
f) -,$\quad$ religiosos
g) - \& , costumbristas

Estos siete grupos elementales básicos se subdividen a su vez, y dilatan el área de investigación, extraordinariamente. Indicaré, sucintamente, las ramificaciones de cada núcleo, para intentar, en la conclusión, la respuesta categórica: 


\section{a) ELEMENTOS POLITICOS}

El estudio de la política española, a pesar de su enorme variedad, puede concretarse en 5 series de elementos sustanciales: I. ${ }^{\mathrm{a}}-\mathrm{La}$ inspiración religiosa; $2{ }^{2}{ }^{2}-\mathrm{La}$ finalidad económica; $3{ }^{a}$ - La realidad peninsular; $4{ }^{a}$ - Las normas de Indias; $5 .{ }^{2}-$ La verdad americana.

Primera serie.-La Inspiración religiosa.-Dos hechos singulares nos confirman esta realidad histórica: la promesa de ayuda a Colón, por los Reyes Católicos, para el viaje a las Indias, después de acabar la expulsión mora de Granada en I492; y la cédula real de Arévalo de zo de mayo de $\mathbf{1 4 9 5}$, en que las Magestades Católicas autorizaban el viaje de sus súbditos a América, porque "descubrirse las dichas tierras, resgatar ellas y poblartas de cristianos, es servicio de Dios Nuestro Señon porque la conversión dellos podría atraer a los que habitan en la dicha tierra, al conocimiento de Dins Nuestro Señor y reducirlos a nuestra Santa Fe Catốlica"

¿No sabemos, tamblén, que ê reino đe Navarra fué arrebatado por excornuniónclel Papan Ytrlio II, a la reina Catalina de Foix, y entregado a Fernando de Aragón, el rey Católico?

Aún antes de la tarde sangrienta de Cajamarca, una cédula real de ${ }^{5} 5^{18}-24$ de setiembre-prohibía venir a Indias, a los condenados por herejía o apostasía, y hasta a sus hijos y sus nietos. En I522, otra cédula, del I 5 de setiembre, cerraba el camino a los moros, a los judíos recién convertidos y a sus hijos. Y, en I570, Felipe II, en Guadalajara, dió su real cédula de primero de febrero, quitando a los gitanos, sus hijos y criados, el derecho de viajar hacia las Indias. 
2." serie.-La finclidad cconómica.-La historia del virreinato del Perú acusa plenamente, la exigencia renovada y angustiosa, de la Corte, a sus colonias, de remesas, ya de tributos ya de préstamos, ya de óbolos graciosos, o ya de contribuciones forzosas. El caso concreto del virrey Chinchón, detallado por Suardo en su "Diario de Lima", poniendo en quiebra a los grandes comerciantes portugueses, es una de las 40 pruebas históricas de la finalidad económica del coloniaje español en América. En el inciso $d$ se condensará el cuadro. Aquí sólo se trata de la finalidad económica, como inspiración política.

3. ${ }^{a}$ serie.-La realidad peninsular.-España, que pudo alcanzar el cetro mundial de Roma, en la Epoca Moderna, si hubiera sabido aplicar ste ingentes recursos, con un plan absorbente de conquista, adolecía de grandes vicios, traducidos, como lo comprueba Menéndez y Pelayo, en desorganización administrativa, en derroches desorbitados, en guerras infecundas con los vecinos, en su alianza rígida con la Curia Romana, en su intransigencia con los movimientos filosỏficòs renovadores en suSdogmatismo, en su abulia, etc. "Jorge Puccinelli Converso»

La circunstancia de que las mejores autoridades virreinales, como Hurtado de Mendoza, Toledo y Castelldosrius, merecieran, entre otros, la desautorización de su política en el Perú, y que, en cambio, se dejara sin sanción a los maleables y dúctiles, que transigieron con el mal, acredita que la Corona no contaba con elementos capaces que orientaran su política, dentro de su propia península.

4." serie.-Las normas de Indias. - Las disposiciones, de orden político, que España dictó, para el gobierno de Indias, califica, inconfundiblemente, su exclusivismo equivocado y la infecundndad de su acción en el continente americano. " . .no dividió nunca el poder-dice Alberdi- 
pues lo conservó todo, hasta el último día de su dominación colonial, en que declaró, ya fuera de tiempo, al pueblo de sus colonias, parte integrante de la monarquía española. Ai revés de Inglaterra, le mandó, desde Europa, no sólo sus mandatos, sino hasta sus últimos funcionarios".

Cabría agregar aún: la prohibición, a sus funcionarios, de vincularse a las colonias por el matrimonio; y el envío de maleantes-el caso del batallón Talavera-para conservar el orden y defender su autoridad, cuando ya apuntaban, en el Perú, los primeros movimientos reaccionarios.

5." serie.-La verdad annericana.-La prevalencia de la nobleza peninsular en el Perú, como en los demás pueblos del continente hispano; los fueros personales odiosios; el abuso de autoridad permitido; la prestancia enorme del clero; la postergación de los segundones; la desopinión de los mestizos; la humillación del indígena; la esclavitud del negro y muchos elementos más, indican que América, uncida al carro del conquistador, no formaba una entidad valiosa en el plano politicolatsea, aque ta verdad americana era una resultante distinta ede lacquellplaneabarsoneía la Corte española. Y lo más grave todavía, que esta situación no constituía, para la Metrópoli, una preocupación intensa, como debería serlo para cualquier colonizador inteligente.

\section{b) FLEMENTOS LEGALES}

El examen comprensivo de la legislación española, que normaba la vida colonial del Perú, conduce, necesariamente, a las siguientes conclusiones: desconectada de la realidad americana; inaplicable; confusa; variable; complejisima; irrespetada; ineficaz, etc. La calificación panorámica, que la historia formula, es ésta: 
Desconectada de la realidad americana.-Los legisladores españoles sólo conocían las colonias a través de informaciones interesadas, desfiguradas e incompletas. Tanto es así que Hurtado de Mendoza por ejemplo, que deportó a algunas docenas de maleantes explotadores, recibió, en recompensa absurda, la rehabilitación de algunos, ennoblecidos en la Corte. De otro lado, la pugna de intereses, entre los encomenderos y los indios, entre los corregidores y los súbditos, entre el cura y la masa, se resolvía, legalmente, a dos mil leguas de los lugares donde debían aplicarse las normas solucionadoras. Con criterio humanista moral y religioso se legislaba; pero, a lespalda de la realidad americana.

Inaplicable.-Legislación teórica, irreal, no podía ser aplicada en el Perú. La prueba absoluta, que produjo hasta un cambio sustancial en el régimen político, creándose las Intendencias, sustitutoras de los corregimientos, la dió Condorcanqui, agotánđose en la defensa del indígena por todos los medios legales. Lo que significa que la legislación española demasiado avanzada para su época no contemplaba lo que hoy desrementalnenl todalleyrsel hugar en que debe ser aplicada y quienes eran los que debían aplicarla.

Confusa.-La legislación no era clara ni precisa. Un caso concreto determinaba una norma, que se mandaba tener presente para casos semejantes, en latitudes distintas y en circunstancias diferentes. Amontonamiento de leyes, más que recopilación, debe llamarse al conjunto de normas, dictadas por la Corte para sus colonias de Indias. Y la confusión resultaba de la intención conciliadora entre dos cuestiones fundamentales inconciliables: la piedad cristiana con el aborigen explotado, y el interés económico de ampliar, cada vez más, las rentas de la corona.

Variable.-Consecuencia normal del absolutismo po- 
lítico, que rebasa toda ley, el monarca producía una variedad infinita de disposiciones, que aclaraban, ampliaban, restringían o interferían las existentes. Donde, con más claridad se percibe esta desarmonía, es en el ángulo judicial. Los fallos de los tribunales, que prestigian la justicia de los pueblos, porque entrañan una aplicación técnica del espíritu legal de una época y que deberían ser intangibles por esencia, no eran respetados por los soberanos españoles. Se les modificaba y anulaba, frecuentemente. ¡Cuántos condenados por la Real Audiencia de Lina, merecieron, en los alcázares reales, verdaderos homenajes!

Complejísina.-España ușaba el pésimo sistema-que el Perú actual sigue, inexplicablemente-de ampliar y renovar su legislación, dejando subsistentes muchas normas de leyes revocadas que, si bien quedaban invalidadas, en cuanto se oponían a las nuevas, mantenían su vigor en la parte armónica. El estudio de una instituta legal requería una minuciosa confrontación de todas las disposiciones semejantes, dictadas a trayés de centenios. De ahí que, la Recopilación de Leyes de Indias, la Auevaly fa Novísima, al lado del Código de ras Py Paiftidlas, dev frifero Juzgo, de las Leyes de Toro de las múltiples Ordenazas y reglamentos especiales, fueran tan enmarañadas en su sentido aplicación, que tra frecuente encontrar oposición de preceptos legales y disparidad de criterio, sobre cuestiones similes.

Basta recordar el caso curioso, en los días del virrey Mendoza y Luna, de Diego Valverde, quien prometiera, por escritura pública, no beber vino ni chicha, durante dos años, bajo pena de pagar quinientos pesos de plata ensayada, en favor de los presos del Santo Oficio, si faltaba a su juramento público. A poco, Valverde, en estado de ebriedad, comete un homicidio. Se le procesa por el crimen y, separadamente, por perjurio, para el cobro de la pena de 500 pesos. 
$\mathrm{Y}$, aunque el querellante, en este caso, es el Santo Tribunal, el acusado se excepciona, sosteniendo que su embriaguez. cierta provenía de aguardiente ingerido, pero no de vino ni de chicha, como constaba en el documento público. Y Valverde ganó la cuestión. La causa por perjurio se sobreseyó.

Irrespetada.-La voz real "se oye, pero no se cumple", dice Blanco Fombona. E1 interés del encomendero, del cura, del Alcalde y del Corregidor, no sólo producían las llamadas "hostias sin consagrar"-Pragmáticas cédulas; órdenes, a las que no se ponía el cúmplase virreinal-sino que existían procedimientos especiales para salvar el principio legal, dentro del mismo fraude cometido. Huamán Poma de Ayala indica una serie de estos procedimientos alegales que tanto influyeron en el despertar de nuestra viveza criolla.

Ineficaz.-La infecacia de la legislación española colonial está corroborada, históricamente, por una serie de realidades inobjettables, tales como: desvinculación social; retardo en la administración de justicia; represalias contra los reclamantes de un derecho; Consunación de abusos autoritarios, ete. etc. Puccinelli Converson

\section{c) ELEMENTOS SOCIALES}

Las clases sociales que España importó a América, definieron las distintas categorías conocidas. Desde la cumbre, ocupada por la nobleza peninsular hasta la sima de los. esclavos, la sociedad peruana se fraccionó en sectores distintos, de intereses diferentes, desarmónicos, esterilizantes. La falta de cohesión social desarticuló al Perú en su célula básica: la familia; y en su unidad representativa: el individuo. La calificación ordinaria social, que tenía hondo sentido distintivo, era: el blanco, el mestizo, el mulato, el cho- 
1o. el negro, etc.; y no lo que habría significado una fuerza de compenetración y de armonía: el peruano. De ahí el distanciamiento de las personas, las rivalidades infecundas, trascendientes a las aldeas, a las haciendas, a los pueblos, a las villas y hasta a las ciudades. Todavía hay trujillanos y arequipeños, por ejemplo, que sienten, sinceramente, la superioridad de sus ciudades sobre Lima, en estética y cultura. En los días coloniales, los blasones de Trujilo, más valiosos que los de Lima, auspiciaron distanciamientos entre sujetos de la misma categoría social.

Sin entrar en el análisis de los elementos sociales, innecesario para nuestro objeto, se puede concluir que España disgregó la sociedad peruana; impidió la solidaridad colonial. Lejos de unificar, dividio y debilitó la energía colectiva, el espíritu vernacular tan feéundo en el avance cultural de los pueblos. Sólo a fines del siglo XVIII, la Sociedad Amantes del País, iniciará, veladamente, la formación del sentido de la peruanidad.

\section{d) FELFMENTOS GÜLTURAIFS}

\section{"Jorge Puccinelli Converso"}

El problema, cuyas bases fundamentales estamos planteando, corresponde a este grupo de elementos. Porque el renacimiento es cuestión de cultura. Deberíamos reservar el análisis de estos elementos para el final. Pero, los colocamos en el centro, porque sobre él los inciden todos los demás, y porque no se puede saber si llegaron a proponerse, en el Perú, las cuestiones esenciales de la cultura occidental, si antes no se esbozan las relidades históricas de la mentalidad peruana, en armonía con los otros factores coincidentes, que completan el panorama vital del Perú de aquella época.

España nos envió su mejor cultura. San Marcos fué, formal y esencialmente, una imagen de Salamanca. Y Sa- 
lamanca fué una reproducción de la célebre de Bolonìa, depositaria y retenedora de la alta sabiduría filosófica y científica de Europa. Pero, ni Salamanca, ni San Marcos rindieron los frutos culturales que hubieran podido producir, sin las normas procústicas que las limitaban. Se creía, por aquellos siglos, que Tomás y Agustín habían sido los faros de la sabiduría; que, más allá de donde ellos vieron la verdad universal, no era lícito ni tolerable escudriñar.

La gran sentencia coránica-grande en monstruosidad-de los mahometanos, contagió a los sabios españoles. Reviviéndola, debieron decirse: la verdad verdadera es la señalada por Agustín y por Tomás; intentar sobrepasarlos, es alarde punible; Santo Tomás y San Agustín son invulnerables. ¿Cómo admitir, en efecto, una conclusión filosófica contraria a la verdad iluminada de los Padres de la Iglesia? Y la Teología encerro, en sus anillos formidables, el campo cultivable de la mente. $Y$ el saber se estancó, se parealizó. Las inteligencias inquietas, detenidas par la aureola deslumbrante de los grandes maestros, se esterilizaron, se perdieron. Biblioteca de Letras

El PerúJ colonialctuvo,llindudablemente, oradores sagrados estupendos; filósofos notables de las congregaciones religiosas; científicos famosos, latinistas eximios; un Caviedes admirable; un Peralta Barnuevo Rocha y Benavides, que todo lo sabía. ¡Claro! ¿Quién no se siente sabio, si el saber tiene por límites explicativos, una matafísica teológica? Si Edison hubiera adelantado su venida, y el fonógrafo hubiera repetido una lección de San Agustín, en los cláustros rígidos de San Marcos, tanto maestros como discípulos, habrían creído encontrarse frente a una máquina sabia, quē dictaba, por permisión divina, una página inmortal. Tal el sentido de la sabiduría de la época: repetir textualmente al Magister. 


\section{e) ELEMENTOS ECONOMICOS}

No es preciso que analicemos las características de la economía española en el Perú, durante la colonia. Es bastante señalarlas ya que las numerosas investigaciones en este ángulo, las han calificado suficientemente.

El monopolio, el exclusivismo, el control permanente, etc., produjeron la emigración de la riqueza del Perú, hacia España, de un lado. Por otra parte, el abandono de la gran industria agraria del período incaico, suplantada por la minería, desvió la enorme energía especializada del aborigen y, por lo mismo, la finalidad económica del país.

La calificación de colonia riea que tuvo el Perú fué, incuestionablemente, como productora, como portadora de riquezas a España, no como país beneficiado con la maravilla productiva de su suelo. El caso histórico del virrey Ladrón de Guevara, que prefirió invertir, en caminos, puentes y templos, en el Perú, parte de la tributación indigena, y que fuera destituído, porfalsaslemputaciones, explica la orientación económica de la dKetrốpolinen sto más rica y poblada colonia de América.

\section{f) ELEMENTOS RELIGIOSOS}

España no quería que América fuese un campo posible de convulsiones religiosas. Evitó que la Reforma, con su aura liberadora del "libre examen", sembrase la duda en las Indias. La duda, que es el comienzo de toda liberación de concieneia. Y su política, su legislación, sus enormas culturales y su economía, tendieron a aquella finalidad. Era natural por consiguiente, que el espíritu religioso participara en la obra conjunta. 
En efecto, la célebre Recopilación de Leyes de Indias-Ley I, Tit. I; Libro IV; Tomo II- ¿No establecía claramente: "el fin principal que nos mueve a hacer nuevos descubrimientos, es la predicación y la dilatación de la Santa Fe Católica, y que los indios sean enseñados y sirvan en paz"?

¿No sabemos que la administración pública fué modelada por la Iglesia? ¿Las divisiones territoriales, las jurisdicciones civiles, las famosas Reducciones de indios, no se basaron en la organización eclesiástica? ¿Los Corregimientos, no correspondían a los curatos?

Las nociones geográficas, los estudios de hidrografía regional, de la flora y de la fauna, eran elaborados por religiosos, los hombres sabios y capaces de la época. Las Misiones, no sólo perseguían la catequización de infieles sino el establecimiento de conventos y escuelas, y la industrialización de las zonas ganadas a los salvajes.

Además, los conflictos autoritarios, las disensiones intimas en el Berú colonial, la acción agobiadora del cura sobre el manso indígena, y muchas otras cuestiones similares, comprueban ep privilegio y la prestancia del factor religioso, dominante en todas las conciencias desde el confesionario, el púlpito, y la escuela, hasta lo más íntimo y sagrado del hogar.

Si la conquista del Perú se hizo por la espada, para la imposición de la cruz; el alma colonial se forjó por la cruz, para la fácil explotación de la espada. El sincronismo era perfecto.

\section{g) ELEMENTOS COSTUMBRISTAS}

Nuestro riquísimo folklore colonial, apenas recogido en mínima parte, nos dice, sin embargo, de la vida peruana 


\section{$-43-$}

del virreinato, en todas su matices. Vida compleja; variadísima; conservadora en ciertas capas sociales; liviana en otras; nos advierte de un fenómeno, fenómeno original, comprobado históricamente: la realidad de algunas costumbres avanzadas, en contraposición a las normas férreas de la moral y de la religión dominantes.

Estos elementos son, por consiguiente, los más importantes para el planteo del problema propuesto. Porque, de ciertas costumbres coloniales del Perú, podemos inducir que vivíamos en pleno Renacimiento, mientras, ideológicamente, en el área de la sabiduría, vegetábamos, incuestionablemnte, en el medioevo.

Efectivamente, al lado de la inquietud religiosa por la bendición de las comidas, por la señal de la cruz, desde el despertar hasta el final del día; por la misa; por el Angelus; por la confesión; por la limosna para el santoral preferido; por la plegaria permanente, ante el miedo del pirata o de los sismos frecuentes; por las plañideras y los pobres de hacha etc,; etc.oteníamos las fiestas, plenas de paganismo, del indio; la jarana, del mestizo, en torno a la imagen sagrada; la liviandad en los tipos más elevados; la fruición social ante el anónimo calumnioso; la frecuencia del divorcio en el siglo XVIII, como lo hace constar Amadie F. Frezier: "Es increíble a qué extremo se lleva este abuso: todos los días se ven gentes que se descasan, con tanta facilidad, como si el matrimonio no fuera sino un contrato civil, por simples quejas de desinteligencia, de falta de salud, o de simple descontento . . . . ."

\section{EL PROBLEMA}

Conocidos ya los elementos fundamentales, podemos plantear el problema: 
nial? ¿En qué momento histórico se descubre el arte del Renacentismo peruano?

Debemos advertir, adelantándonos a las objeciones que pudieran formulársenos, que damos por sentado el sentido del Renacimiento europeo: el derecho individual de ir a las mismas fuentes de la sabiduría antigua, para formar juicio personal sobre la verdad. Más simplemente el derecho de tener conciencia de la propia individualidad. O sea, comprender, en vez de retener.

De este modo la cuestión se simplifica y aclara, para la solución que buscamos. Solución que debe aflorar, como respuesta, a cada una de las interrogaciones siguientes:

Primeras ¿Hubo renacimiento en el campo de la filosofía? No, categóricamente.

En San Marcos se conocieron y tradujeron a los clásicos griegos y latinos. Se repetían de memoria, páginas enteras, en griego, de Platón y Aristóteles; y en latín, de Horacio y de San Agustín. Las lecciones de los grandes maestros eran repeticiones invariables de las viejas pláticas. El escolasticismo imperaba y resistia las falaces acometidas del probabilismo, excluído como peligroso y nocivo a la verdad consagrada. Y, cuando Toribio Rodríguez de Mendoza inicia su obra acogedora, exponiendo las nuevas orientaciones de la filosofía contemporánea el Santo Tribunal interviene, y el maestro renovador es silenciado en el claustro frío..

En los días fulgentes de la emancipación, cuando Rousseau llega al Perú, se le cita; se le sigue, se le repite; se acepta, sin beneficio de inventario, su idealismo. No se le comenta. Se le ingiere. No se le asimila. Y tenía que ser así. No en balde nuestra mentalidad, canalizada más de dos siglos y medio, había perdido el poder de discernir.

Todavía, en nuestra república, seguíamos sin renaci- 
miento filosófico. A prinicipios de este siglo, por el año I902, con excepción de Deustua, que agitó y sacudió nuestra mentalidad, abriendo horizontes nuevos, en métodos y en doctrinas; de Javier Prado, que sentía la fruición del maestro, indagando en las teorías de los grandes filósofos, y de Luis Miró, que divulgaba interesantes nociones de Pedagogía, el Perú asistía al espectáculo acerbo de maestros sanmarquinos que creían, sinceramente, que la verdad úni$\mathrm{ca}$, indiscutible, se encerraba en las páginas absurdas de sus textos escolásticos .....

Por consiguiente el renacimiento en el ángulo filosófico, es un fenómeno del presente en el Alma Mater nacional. Luego, históricamente, el Instituto Superior de Cultura, en el Perú, seguía el diapasón del medioevo, mientras la sociedad peruana, en algunas de sus costumbres, había encontrado el ritmo de la cultura contemporánea.

Segunda: ¿̇Hubo Renacimiento en el ángulo legal? No, categóricamente.

Sin necesidad de alegar razones de los días virreinales, tenemos una prueba abrumadora en ef Título Segundo de la Sección Tercera del Codigol Civinde 852 , vigente hasta noviembre de 1936. El artículo I32 decía: "Por el matrimonio se unen perpetuamente el hombre y la mujer. ..." El I34 establecía: "El matrimonio, legalmente contraído es indisoluble; acábase solo con la muerte de alguno de los cónyuges..." Y el I 39, rematando el criterio legal sobre esta institución, dejaba "íntegros los deberes que la religión impone". Es decir, que el matrimonio, en el Perú, hasta hace menos de tres años-salvo la ley de divorcio y matrimonio civil obligatorio dictada por la Junta de Gobierno que presidiera el general Sánchez Cerro-se mantenía tal y como lo definiera el Concilio de Trento en I 545. (Diez años después de fundada Lima.. O sea, perpetuo e indisoluble. 
¿Cómo discurrir, frente a la paradoja tremenda que la historia apunta en el Perú colonial del siglo XVIII? ¿Cómo explicar que la ley mantenga, hasta 1936, los mismos principios del Fuero Juzgo de Alonso el Sabio, en pleno medievo, cuando Lima, en I7r3, según la cita de Frezier, había burlado, en la práctica, la perpetuidad, y roto, en la realidad de la vida, la indisolubilidad medieval?

En conclusión: la legislación sustantiva del Perú acabo de entrar en el período renacentista, rompiendo las normas clásicas; mientras la sociedad vivía, en la realidad limeña, desde el año I700, con dos siglos de adelanto sobre nuestra cultura legal.

Tercera: ¿̈Hubo Renacimiento literario y artístico? No, relativamente.

Las inquietudes - vitales del coloniaje (herejía y piratería); las normas rígidas de educación; los patrones insalvables de la instrucción; el control enorme de todas las actividades hominales etc., impidieron el florecimiento de una rica literatura, y, en general, de todas las bellas artes. Caso típico interesante, que prueba como ta autoridad cremaba los alardes renacentistasen ef airte, es el dé Juan del Castillo, en tiempo del marqués de Montesclaros, coronado el ro de julio de 1608 , con el auto de fe que le eliminaba de la vida, por una polémica oratoria ingenua con el domínico Rodrigo de Azula.

Si había peligro de vida para el osado que intentase salir del medievo, ¿quién se atrevería a perseverar en el camino de la luz?

Empero nuestro folklore nos cuenta anónimamenteúnica forma en que la cultura se condensa en chispazos de ingenio colonial-de avances formidables literarios y artísticos que dicen del progreso mental de un sector social del Perú colonial. La protesta verbi gracia contra el otor- 
gamiento del Doctorado en San Marcos, a Jorge Escobedo, protegido del virrey de la Croix, en I788, es de una elocuencia superlativa:
"Si en Roma el emperador
Calígula, por su mano, declaró Cónsul romano
a su caballo andador
no es de extrañar que el Rector,
como quien se tira un edo
por su sola autoridad,
haya hecho miembro a Escobedo
de aquesta Universidad"

Y son, también, elocuentes los dardos sistemáticos que Caviedes, el "Poeta de la Ribera" dispara contra los físicos de la época.

Cuarta: No nos extenderemos en la búsqueda del renacimiento peruano en el campo político, ni en el económico, ni en el religioso. De principio a fin del virreinato, se mantienen inalterables estos elementos, a pesar de las frecuentes representaciones a la Corte, en favor de los indígenas; de las interferencias religioso civiles; del contrabando y piratería, etc. No admitiéndose, oficialmente, el discernimiento en el campo de la cultura; la política, la economía y la religión tuvieron que conservar sus posiciones clásicas del medievo.

Quinta: ¿̈Hubo Renacimiento en el ángulo costumbrista? Si, positivamente, ampliamente.

Desde fines del siglo XVI, cuando la virreina Teresa de Castro trajo su pequeña corte, para ampliar la sociabilidad limeña, la acción femenina se dejó sentir con gran eficacia. En i6or un gran mitín en la Plaza de Armas apo- 
yado por todas las faldas de Lima, impidió la promulgación de la pragmática real de 1600 , que prohibía el uso de ciertos vestidos a las mujeres honestas.

¿Por qué sin derecho contra la moral de la época negándose a respetar el consejo de la Iglesia, las mujeres limeñas obtuvieron aquel triunfo tan sonado? Porque ellas, contra la autoridad, contra la ética y contra la religión, usaban un derecho formidable. Porque vivían en pleno renacimiento, mientras los mandatarios se conservaban en el medievo.

Por qué las mujeres de Lima, mantuvieron la saya y el manto, contra la amenaza de excomunión arzobispal? Porque la saya y el manto eran el vehículo adecuado al renacentismo espiritual de la mujer peruana, contra el conservadorismo mental de los hombres y de las instituciones de la época. $Y$, porque, según el inteligente observador Lizárraga, en su "Descripción breve de la tierra del Perú, Tucumán, Río de la Plata y Chile": "de las mujeres nacidás en esta ciudad, (Lima) nno tenge que decir sino que hacen mucha ventaja a los varones; perdónenme por escribirlo, y no lo escribiría sino fuera notísimo".

El folklore colonial peruano, no obstante lo poco que hemos recogido, testifica, en varias facetas de la vida, que la sociedad del Perú, en su clase menos privilegiada, sintió hondamente el renacimiento; vivió, en su plenitud, el momento espiritual liberador del renacentismo europeo.

\section{CONCLUSIONES}

Ante el problema histórico que hemos planteado, y frente a las soluciones parciales que ya apuntamos, se pueden formular las dos conclusiones siguientes: 
Primera: El Renacimiento no afloró en el Perú colonial en ninguno de los campos de la alta cultura. Sólo, en el plano emocional de las Bellas Artes, hubo alardes moderados, tímidos de renacentismo.

Segunda: En el ángulo social la conclusión es doble: oficialmente, la sociedad peruana mantenía su régimen medioeval; en la intimidad de la vida, en sus costumbres avanzadas, no sólo conoció, sino que superó al renacimiento.

J. M. VAlega.

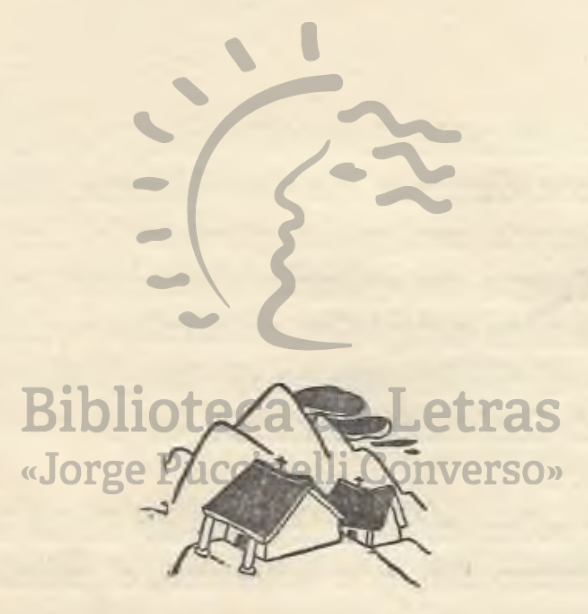

